ARTICLE

\title{
Sexual function and ageing
}

\author{
L Geffen, MB ChB, FCFP (SA) \\ Institute of Ageing, Faculty of Health Sciences, University of Cape Town, South Africa
}

Corresponding author: L Geffen (lgeffen@gmail.com)

The development of medications for the treatment of erectile dysfunction in men has, on one level, medicalised the notion of sexual dysfunction. However, it has also allowed researchers to explore many other aspects of sexual function in older persons. Health and wellbeing are positively affected by sexual activity. Older persons engaging in regular consensual sex have shown improved well-being in both physical and psychological health, associated with fewer health problems as they age. Engaging in intercourse has been correlated with improved intimate relationships, improved cardiovascular health and lower rates of depression.

S Afr Med J 2014;104(6):450. DOI:10.7196/SAMJ.8396

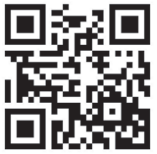

As people age, changes in physical and mental health, relationship status and societal pressures contribute to sexual function. Health and well-being are positively affected by sexual activity. ${ }^{[1]}$ While there is currently no single internationally accepted definition of sexual function, DeLamater ${ }^{[2]}$ defines it as the ability to engage in sexual expression and sexual relationships that are rewarding. It is the state of one's physical, mental and social wellbeing in relation to one's sexuality. ${ }^{[2]}$ Sexual function is therefore a complex relationship between physiological factors, physical health, mental health, social relationships and societal norms associated with ageing and sexuality. ${ }^{[2]}$ More people are growing older than ever before, and expectations of sexual well-being need to be recognised by society in general and healthcare professionals in particular.

\section{Demography of ageing}

Over the next three decades the number of people over the age of 60 is expected to rise from $\sim 810$ million ( 1 in 9 persons) to over 2 billion (1 in 5), with the fastest growing segment being in low- and middleincome countries. ${ }^{[3]}$ In South Africa, life expectancy at birth has increased from 52.1 years in 2003 to 59.6 years in 2013, and as of 2011, 8\% of the South African population is over the age of $60 .{ }^{[4]}$ As society ages, the healthy life-years lived increase.

\section{Sexual behaviour}

To date, the two largest studies on sexual health and function that include older persons are the National Social Life, Health, and Aging Project (NSHAP) ${ }^{[1]}$ in the USA and the third National Survey of Sexual Attitudes and Lifestyles (Natsal-3) ${ }^{[5]}$ in the UK.

A total of 3005 people aged between 57 and 85 years were surveyed in the NSHAP. Sexual activity was defined as 'any mutually voluntary activity with another person that involves sexual contact, whether or not intercourse or orgasm occurs'. ${ }^{[1]}$ The prevalence of sexual activity, and that of persons who rated that having sex was not at all important, in the foregoing 12 months are shown in Table 1. Sexual activity declined with age and was lower among women than men. Of the sexually active men and women aged 75 - 85 years, 54\% reported having sex at least $2-3$ times per month. The NSHAP showed that the majority of older adults were engaged in an intimate relationship and regarded sexuality as an important part of life. A substantial number of men and women engaged in vaginal intercourse, oral sex and masturbation - even in the eighth and ninth decades of life.

\section{Health and sexual behaviour}

The NSHAP showed that poorer health was significantly associated with being less sexually active. ${ }^{[6]}$ The most commonly reported reason for sexual inactivity over a 3-month period in persons involved in an intimate or spousal relationship was the male partner's physical health. Men and women with diabetes were less likely to be sexually active. The Natsal-3 reported that men and women with a longstanding illness, $\geq 2$ chronic conditions, a BMI $>35 \mathrm{~kg} / \mathrm{m}^{2}$ or who walk up stairs with difficulty due to a health problem were significantly less likely to report sexual activities in the prior 4 weeks than those who did not report these issues. ${ }^{[5]}$

Depression, coronary artery disease, renal failure, lower urinary tract symptoms in women, hyperprolactinaemia, diabetes mellitus, primary or secondary hypogonadism in men, and neurological diseases, e.g. cerebrovascular disease and Parkinson's disease, are all associated with reduced sexual desire and arousal. ${ }^{[7]}$ These conditions are more common in older persons. Medications such as antipsychotics, beta-blockers, antidepressants, anti-androgens (e.g. spironolactone), anti-epileptics and narcotic analgesics have been shown to reduce sexual function. ${ }^{[7]}$

Since the advent of combination antiretroviral therapy, HIV/ AIDS is now a chronic condition, and as the population ages it is expected that the number of older persons living with HIV will grow. In a 2008 surveillance study, HIV prevalence rates among South African women and men $\geq 60$ years were estimated to be $9 \%$ and $4.2 \%$, respectively. ${ }^{[8]}$ However, older people are often perceived as no longer being sexually active, ${ }^{[9]}$ resulting in them not being screened

Table 1. The NSHAP prevalence of sexual activity

\begin{tabular}{llll}
\hline & \multicolumn{3}{c}{ Age (yrs) } \\
\cline { 2 - 4 } & $\mathbf{5 7 - 6 4}$ & $\mathbf{6 5 ~ - ~ 7 4}$ & $\mathbf{7 5 ~ - ~ 8 5 ~}$ \\
\hline Prevalence of sexual activity, \% & 73 & 53 & 26 \\
Sex rated as not important, \% & 15 & 25 & 41 \\
NSHAP = National Social Life, Health, and Aging Project. & &
\end{tabular}


effectively for HIV and limiting the appropriate therapies for older sexually active persons.

\section{Relationship status and impact on sexual behaviour}

The NSHAP demonstrated that women were less likely to be in a marital or intimate relationship at any given age and this difference increased with age. ${ }^{[1]}$ Of those women not in an intimate relationship, $4 \%$ reported being in a sexual relationship in the prior 12 months, as opposed to $22 \%$ of men. The prevalence of sexual problems encountered by men and women reported in the NSHAP is shown in Table 2, as well as the percentage of individuals bothered by these problems.

\section{Problems specific to women}

Menopause is a physiological process. It is associated with reduction in oestrogen production and the resulting loss of reproductive ability. ${ }^{[10]}$ Societal values have associated menopause with loss of attraction and sexual success, which are associated with youthfulness. ${ }^{[10]}$ Physiological changes due to menopause are: reduced genital blood flow, reduced lubrication of the vagina and reduced genital sensation. Vaginal atrophy, loss of elasticity, introital stenosis and dyspareunia are often associated with postmenopausal changes. ${ }^{[10]}$ Vaginal dryness has been associated with a previously fractured hip or pelvis, a hip replacement, depressive symptoms, being postmenopausal, and having backache or bone disease for $>3$ months in the past year. ${ }^{[5]}$ In postmenopausal older women, vulvovaginal atrophy (VVA) is a progressive problem, which is unlikely to resolve without treatment. ${ }^{[11]}$ Surveys have found that $19-27 \%$ of women report dryness, irritation or itching. Up to $80 \%$ of women have found it to affect their quality of life, while $7 \%$ reported that their healthcare practitioner raised the problem. ${ }^{[1]}$

\section{Management of vulvovaginal atrophy}

The North American Menopause Society recommends a stepwise approach to the management of VVA: ${ }^{[1]}$

- For mild to moderate symptoms, non-hormonal vaginal lubricants and moisturisers as well as regular sexual activity with a partner, solo or a device are advised.

- For more severe symptoms, vaginal oestrogen creams are advised.

- Oestrogen creams have been shown to be systemically absorbed.

- The risks of harm need to be weighed up in:

- women at risk of venous thromboembolism

- women with an intact uterus

- women with oestrogen-sensitive breast cancers.

\section{Screening questions for women} presenting for periodic health reviews It is recommended that women presenting for a periodic health review are asked the following three screening questions: ${ }^{[10]}$

- Are you sexually active?

- Are there any problems?

- Do you have pain with intercourse?

\section{Problems specific to men}

Andropause is a term used to describe age-related androgen decline. ${ }^{[12]}$ There is no internationally accepted clinically defined entity, and unlike menopause, which causes reproductive failure in women, men can continue to reproduce until the end of their lives. While levels of testosterone do decline as men age, these are of a physiological nature rather than of complete androgen failure. Doctors need to be mindful of age-related conditions being defined as a disease state, once new products are developed and believed to alleviate or attenuate associated symptoms without sound evidence of benefit. ${ }^{[13]}$

The known prevalence of complete androgen failure is $0.5 \% \cdot{ }^{[12]}$ The off-label use of testosterone replacement has increased significantly worldwide. ${ }^{[12]}$ In the USA, testosterone use has increased five-fold from 2000 to 2011, with almost 5.3 million men using it. ${ }^{[14]}$ In men with established coronary artery disease using testosterone, the absolute risk of rehospitalisation, death, myocardial infarction and stroke showed an increase of $5.8 \%$ over 3 years. ${ }^{[15]}$

While multiple medical risk factors are associated with erectile dysfunction (ED), age is the greatest risk factor. ED is found in $20-40 \%$ of men aged $60-69$ years and increases to $50-100 \%$ in men over $70 .^{[14]}$ Sildenafil, vardenafil and tadalafil are all phosphodiesterase type-5 inhibitors (PDE5-Is) registered for the treatment of ED. ${ }^{[14]}$ They are effective in reducing ED by up to $65 \%$ and associated with no increase in myocardial infarction or death, cardiac ischaemia or cardiac haemodynamics on exercise testing. ${ }^{[14]}$ They are contraindicated with the concomitant use of nitrates, which may result in severe hypotension. ${ }^{[14]}$ Testosterone supplementation together with PDE5-Is is successful in men $\geq 65$ years who have low testosterone concentrations and who are initially unresponsive to PDE5-Is. ${ }^{[14]}$

\section{Doctor-patient relationship}

It is estimated that only $38 \%$ of men and $22 \%$ of women discuss sex with a doctor after the age of $50 .^{[1]}$ It is possible that poor communication between doctors and their patients is due to the unwillingness of both parties to initiate the discussion, confounded

Table 2. The NSHAP prevalence of sexual problems

\begin{tabular}{|c|c|c|c|c|}
\hline & \multicolumn{2}{|c|}{ Men } & \multicolumn{2}{|c|}{ Women } \\
\hline & Prevalence, \% & Bothered, \% & Prevalence, \% & Bothered, \% \\
\hline Achieving/maintaining an erection & 37 & 90 & & \\
\hline Lack of interest & 28 & 65 & 43 & 61 \\
\hline Climaxing too quickly & 28 & 71 & & \\
\hline Performance anxiety & 27 & 95 & & \\
\hline Inability to climax & 20 & 75 & 34 & 59 \\
\hline Difficulty with lubrication & & & 39 & 68 \\
\hline Finding sex not pleasurable & & & 23 & 64 \\
\hline Pain at vaginal entry & & & 17 & 97 \\
\hline
\end{tabular}


by age and sex differences. Attitudes about sexuality, especially as people grow older, may also inhibit discussions.

It has been reported that $70-90 \%$ of women are willing to discuss sexual behaviour with their healthcare provider and require information about sexual well-being. However, most of them hope that the healthcare professional will raise the issue. ${ }^{[10]}$ In a study of sexual healthcare needs of women $\geq 65$ years, $68 \%$ of women reported that the topic of sexuality had never arisen in a consultation, while $79 \%$ would have discussed the topic had it been initiated by a doctor, and $97 \%$ believed that it was important for a doctor to know about their sexuality. ${ }^{[16]}$

The number of medical doctors with an interest in sexual medicine has remained constant since the 1970s and studies have shown that doctors often look to non-medical therapists for help in managing sexual problems. ${ }^{[10]}$

A significant number of people are stigmatised owing to their sexual orientation. Family practitioners need to provide a space for older patients from sexual minority groups (many of whom have grown up marginalised and stigmatised owing to their sexual orientation) to discuss their sexual health and be afforded the care that they need as they age.

\section{Conclusion}

Sexual activity and problems associated with sex are common among older persons. It is important that healthcare professionals become knowledgeable about the sexual practices of their older patients. Improved knowledge may translate into improved information for patients and the ability to identify treatable problems, enhancing the quality of life and well-being of older persons.

\section{References}

1. Lindau ST, Schumm LP, Laumann EO, Levinson W, O'Muircheartaigh CA, Waite LJ. A study of sexuality and health among older adults in the United States. N Engl J Med 2007;357(8):762-774. [http://dx.doi.org/10.1056/NEJMoa067423]

2. DeLamater J. Sexual expression in later life: A review and synthesis. J Sex Res 2012;49(2-3):125-241. [http://dx.doi.org/10.1080/00224499.2011.603168]

3. Population Ageing and Development 2012 Wall Chart. http://www.un.org/esa/population/ publications/2012PopAgeingDev_Chart/2012AgeingWallchart.html (accessed 25 March 2014).

4. Statistics South Africa. Mid-year population estimates 2013. Report No. P0302:16. http://www.statssa. gov.za/publications/statsdownload.asp?PPN=p0302\&SCH=5500 (accessed 25 March 2014).

5. Field N, Mercer CH, Sonnenberg P, et al. Associations between health and sexual lifestyles in Britain: Findings from the third National Survey of Sexual Attitudes and Lifestyles (Natsal-3). Lancet 2013;382:1830-1844. [http://dx.doi.org/10.1016/S0140-6736(13)62222-9]

6. Suzman R. The National Social Life, Health, and Aging Project: An Introduction. J Gerontol B Psychol Sci Soc Sci 2009;64B(Suppl 1):i5-i11. [http://dx.doi.org/10.1093/geronb/gbp078]

7. Basson R, Schultz W. Sexual sequelae of general medical disorders. Lancet 2007;369(9559):409-424. . Basson R, Schultz W. Sexual sequelae of general medica
[http://dx.doi.org/10.1016/S0140-6736(07)60197-4]

8. Whallrauch C, Bärnighausen T, Newell ML. HIV prevalence and incidence in people 50 years and older in rural South Africa. S Afr Med J 2010;100(12):812-814

9. Negin J, Cumming RG. HIV infection in older adults in sub-Saharan Africa: Extrapolating prevalence from existing data. Bull World Health Organ 2010;88(11):847-853. [http://dx.doi.org/10.2471/ BLT.10.076349]

10. Lamont J. Female sexual health consensus clinical guidelines. J Obstet Gynecol Can 2012;34(8):769-775. 1. North American Menopause Society. Management of symptomatic vulvovaginal atrophy: 2013 position statement. Menopause 2013;20(9):888-902. [http://dx.doi.org/10.1097/GME.0b013e3182a122c2]

12. Handelsman DJ. Global trends in testosterone prescribing, 2000 - 2011: Expanding the spectrum of prescription drug misuse. Med J Aust 2013;199(8):548-541.

13. Braun SR. Promoting 'low t': A medical writer's perspective. JAMA Intern Med 2013;173(15):14581460. [http://dx.doi.org/10.1001/jamainternmed.2013.6892]

14. Shamloul R, Ghanem H. Erectile dysfunction. Lancet 2013;381(9861):153-165. [http://dx.doi. org/10.1016/S0140-6736(12)60520-0]

15. Vigen R, O'Donnell CI, Barón AE, et al. Association of testosterone therapy with mortality myocardial infarction, and stroke in men with low testosterone levels. JAMA 2013;310(17):1829-1836. [http:// dx.doi.org/10.1001/jama.2013.280386]

16. Nusbaum MRH, Singh AR, Pyles AA. Sexual healthcare needs of women aged 65 and older. J Am Geriatr Soc 2004;52(1):117-122 